\title{
Force-Deformation Study on Glass Fiber Reinforced Concrete Slab Incorporating Waste Paper
}

\author{
S. Praburanganathan $\mathbb{D}^{1}{ }^{1}$ N. Sudharsan, ${ }^{2}$ Yeddula Bharath Simha Reddy, ${ }^{1}$ \\ Chukka Naga Dheeraj Kumar Reddy $\mathbb{D D}^{3}{ }^{3}$ L. Natrayan $\left(\mathbb{D},{ }^{4}\right.$ and Prabhu Paramasivam ${ }^{5}{ }^{5}$ \\ ${ }^{1}$ School of Civil Engineering, REVA University, Bengaluru, India \\ ${ }^{2}$ Department of Civil Engineering, Vidya Jyothi Institute of Technology, Hyderabad, India \\ ${ }^{3}$ Department of Civil Engineering, Aditya College of Engineering and Technology, Surampalem, India \\ ${ }^{4}$ Department of Mechanical Engineering, Saveetha School of Engineering, SIMATS, Chennai, Tamil Nadu 602105, India \\ ${ }^{5}$ Department of Mechanical Engineering, College of Engineering and Technology, Mettu University, Metu, Ethiopia
}

Correspondence should be addressed to S. Praburanganathan; praburanganathan.s@reva.edu.in, Chukka Naga Dheeraj Kumar Reddy; dheerukumbi@gmail.com, and Prabhu Paramasivam; prabhuparamasivam21@gmail.com

Received 11 November 2021; Revised 15 December 2021; Accepted 22 December 2021; Published 12 January 2022

Academic Editor: Md. Akter Hosen

Copyright (C) 2022 S. Praburanganathan et al. This is an open access article distributed under the Creative Commons Attribution License, which permits unrestricted use, distribution, and reproduction in any medium, provided the original work is properly cited.

This study inspects the viability of engaging the discarded paper wastes in concrete by varying the volume proportions from $0 \%-$ $20 \%$ with each $5 \%$ increment in replacement of the weight of cement. A physiomechanical study was conducted, and the results were presented. A glass fiber reinforced rectangular slab with a longer $\operatorname{span}\left(l_{\mathrm{y}}\right)$ to shorter $\operatorname{span}\left(l_{\mathrm{x}}\right)$ ratio of $\left(l_{\mathrm{y}}: l_{\mathrm{x}}\right) 1.16$ was cast with optimum replacement of waste-paper mass and compared the force-deformation characteristics with the conventional concrete slab without waste paper. The optimum percentage of discarded papers for the replacement of cement is $5 \%$. Also, the results imply that the compressive strength at the age of 28 days is $30 \%$ improved for the optimum replacement. Based on the outcomes of the investigation, it can be inferred that the compressive strength gets progressively reduced if the volume of the discarded paper gets increases. The incorporation of glass fibers improves the split and flexural strength of the concrete specimens considerably. The ultimate load-carrying capacity of the glass fiber reinforced waste paper incorporated concrete slab measured $42 \%$ lower than that of the conventional slab. However, development of the new type of concrete incorporating waste papers is the new trend in ensuring the sustainability of construction materials.

\section{Introduction}

Currently, a huge volume of concrete is used in construction due to its properties of easy molding, higher strength, and durability characteristics [1]. However, due to the usage of cement in concrete production, the emissions and carbon footprint are ever increasing [2]. Hence, concrete technology is under constant pressure to innovate novel concrete which has minimalistic emission properties. There are several new types of concrete under research. Also, the accumulation of waste materials from municipal and industrial sources is increasing day by day [3].

The disposal of these waste materials is a point of concern for every municipality or industry [4]. As per the
Central Pollution Control Board of India, the per capita production of solid waste is $0.26-0.85 \mathrm{~kg} / \mathrm{day}$ [5]. Studies reveal that $70-80 \%$ of solid wastes are directly dumped as landfills [6]. Direct landfilling creates environmental issues and health hazards depending on the nature of the waste materials [7]. The optimum solution for this problem is to use the waste material in the construction products [8]. As per the Confederation of European Paper Industries, the paper industry waste is predominantly used in landfills [9], energy recovery, and is used on composting or land spreading [10]. As per the existing research of Agulló et al. [11] and Ahmadi and Al-Khaja[12], the paper pulp has been used as the replacement of mineral filler material in concrete mixes. As per the record, the world paper production is 
around 400 million tons, and it can increase to another 100 million tons in the year 2050 [13]. The disposal of paper waste involves social and economic constraints [14]. The paper waste can be used in bioplastics [15], asphalt [16] and cement products [17], and adsorbent production [18]. As per the latest study of Karimi et al. [19], the paper mass can also be used as a viscosity modifying agent in cement-based materials [20]. Numerous studies are focusing on the energy management [21] and energy efficiency [22] of paper pulpbased products; however, the available literature on using paper waste in the production of concrete products is scarce [23]. Existing research focused towards the use of paper waste with the ordinary portland cement and water mix. This kind of product was termed "Paper Crete." With the use of this new material, blocks were manufactured and tested for the structural properties such as modulus of elasticity and thermal and bond characteristics [24, 25].

Also, Agulló et al. [11] conducted a study based on the incorporation of paper pulp sludge in plaster composite mixtures, and the authors concluded that the wet paper sludge needs to be dried for obtaining good mechanical and rheological characteristics. However, the discarded paper waste concrete is an innovative type of concrete manufactured with the basic ingredients of normal concrete with partial substitution of waste papers in place of cement [22]. It can be inferred from the earlier research that with the use of waste papers, the final product can be obtained with a reduced density [26], improved acoustic [27], and heat insulation characteristics [28]. The disadvantage reported by adding the paper mass is the higher water absorption. By adjusting the water-cement ratio, the concrete can be produced with an equal density as that of conventional concrete. Also, it is suggested to use this material as a roofing element with the addition of necessary reinforcement [29]. The strengthening may be of either (a) chicken wire mesh, (b) glass fibers, or (c) wooden fibers [30]. According to an earlier study, the waste paper mass was mixed with conventional concrete mixture with and without fly ash, kaolin, clay, Rice Husk Ash (RHA), $\mathrm{SiO}_{2}$, and Quartz powder, and physical and mechanical properties were studied, and it was determined that the use of paper induces the reduction in strength properties of concrete. Hence, it was advised to add reinforcements in any form to improve the strength of paper concrete [31]. In this paper, an attempt has been made to engage the glass fibers as reinforcement in the paper concrete. As per the study of Madhkhan and Katirai [32], the incorporation of glass fibers improves the mechanical properties of the final concrete. Waste papers are used as a partial replacement of cement, and the mechanical properties are assessed including the compressive strength, split tensile strength, and flexural strength. These results are compared with specimens containing the glass fibers.

\section{Raw Materials and Brick Mixture Proportions}

Portland cement of 53-grade cement as per BIS 1489 standards [33] is used for this investigation. Crushed stone aggregates with $20 \mathrm{~mm}$ passing and a $12.5 \mathrm{~mm}$ retaining on the Indian Standard (IS) sieve are used. The specific gravity of the aggregate is recorded as 2.62. Natural sand with a specific gravity of 2.6 is engaged for the experimental investigations. The paper mass used for the study has undergone preprocessing stages obtained through several stages. Initially, the discarded waste paper was soaked in water for a minimum period of 72 hours. After obtaining the wet mass, it is ground into fine mass using the wet grinder. The paper mass was sun dried for 24 hours before obtaining the final product (Figure 1). Water-dispersible chopped glass fiber of density $2600 \mathrm{~kg} / \mathrm{m}^{3}$ has been used with the optimum volume proportion of $4 \%$. Figure 2 shows the dispersing process of glass fibers in the concrete. Table 1 presents the properties of water-dispersible chopped glass fibers. Tables 2 and 3 present the physical and chemical properties of the waste paper used in the present investigation.

A concrete mix design of M25 grade corresponding to BIS 10262-2019 standards is engaged with a mix ratio of 1 : $1.12: 2.746$ and limited the water/cement ratio to 0.44 . Table 4 shows the mix proportions for 1 cu.m. of concrete. Accordingly, the fine aggregate and coarse aggregate volume are fixed as $500 \mathrm{~kg} / \mathrm{m}^{3}$ and $1223 \mathrm{~kg} / \mathrm{m}^{3}$.

\section{Methods}

To understand the mechanical properties of discarded waste paper concrete with and without glass fiber addition, specimens were cast by varying the paper residues of different percentages of $0 \%, 5 \%, 10 \%, 15 \%$, and $20 \%$ of the weight of cement. After finding the initial set of outcomes, a constant $4 \%$ volume of glass fiber reinforcement has been added to all the different percentage paper residue mixes, and then, the strength properties have been analyzed.

The dry density of the concrete samples is found by heating the sample in the oven for 48 hours at the temperature of $90^{\circ} \mathrm{C}$, and each sample was weighed for the dry weight. The saturated weight of the sample was found by immersing the specimens in the water tank for three complete days. After the soaking period, the specimens were removed and wiped with a dry cloth and weighed with a digital balance. From the saturated weight and the dry weight, the percentage of absorption was computed.

Compressive strength of the concrete cubes $(150 \mathrm{~mm})$ was found at the curing age of 28 days subject to the vertical load under the compression testing machine. The splitting tensile strength of the cylinder $(150 \mathrm{~mm}$ diameter and $300 \mathrm{~mm}$ high) was obtained for each sample by placing the cylinder specimen horizontally and applying a compressive force on the specimen. The flexure strength of the prism $(100 \times 100 \times 410 \mathrm{~mm})$ was obtained by testing a prism at the curing age of 28 days. The casting of the slab is shown in Figure 3.

Two numbers of two-way slabs of $l_{\mathrm{y}} / l_{\mathrm{x}}$ ratio -1.16 are cast, out of which one slab is cast with conventional mix and the other with optimum replacement of paper mass with water-dispersible glass fiber. The overall dimensions of the slab are $1200 \times 1400 \times 75 \mathrm{~mm}$ with $6 \mathrm{~mm}$ diameter reinforcements at $150 \mathrm{~mm} \mathrm{C/C}$ distance. The support edge condition is simply supported in all corners. The test is performed under a loading frame. A hydraulic loading Jack 


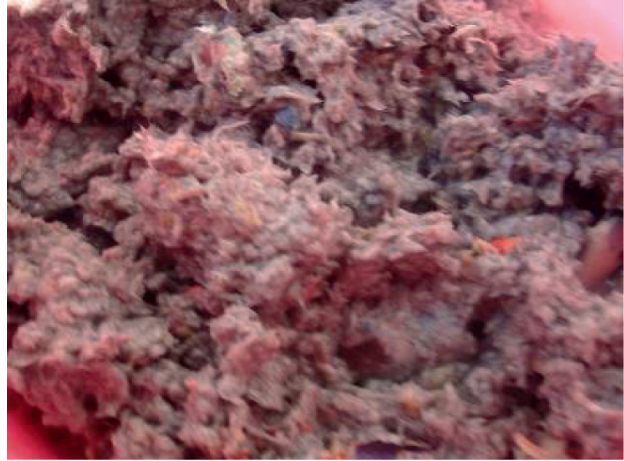

(a)

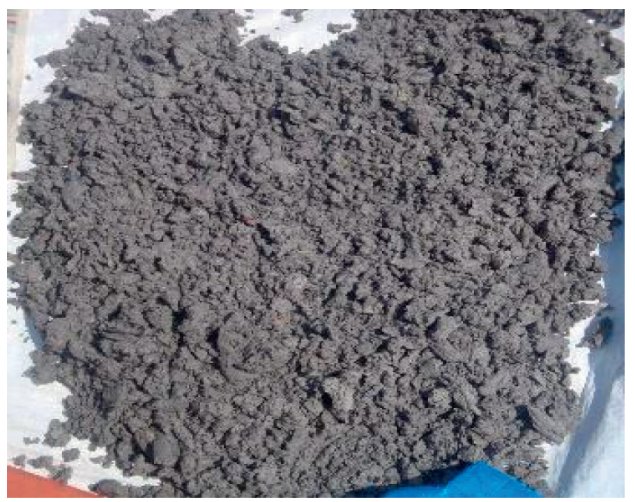

(c)

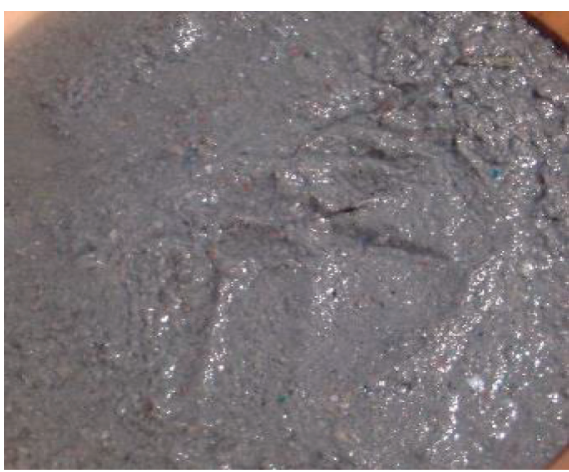

(b)

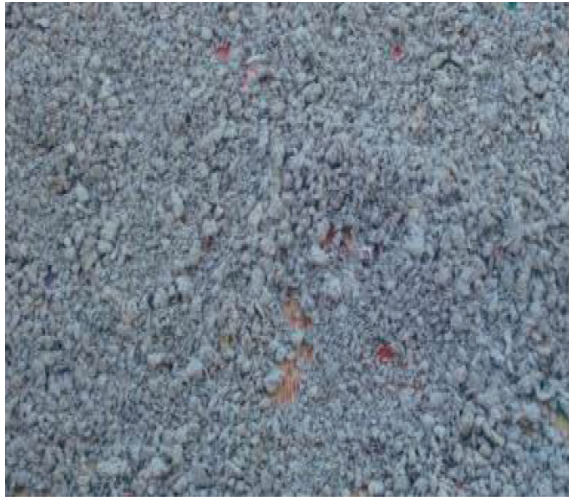

(d)

Figure 1: Preprocessing process of paper waste. (a) Wet mass. (b) After grinding. (c) During sun drying. (d) Final mass.

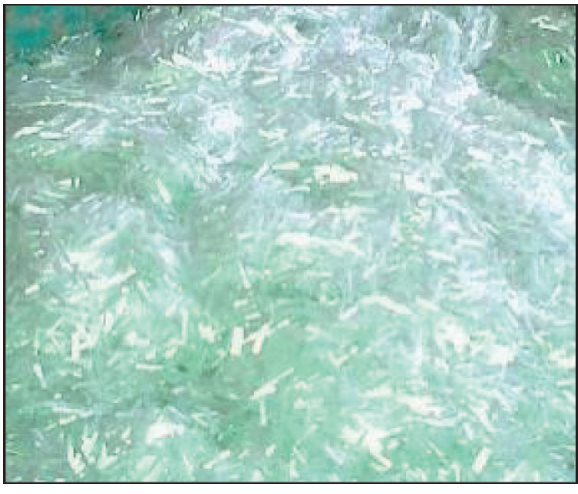

(a)

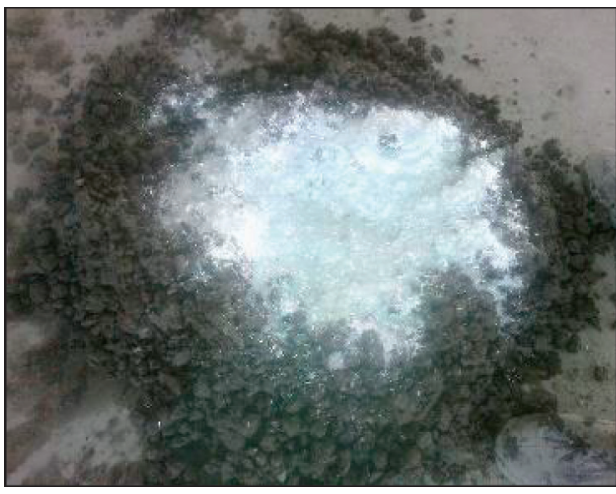

(b)

FIGURE 2: Glass fiber mixing procedure. (a) Dispersing of the glass fiber in the water; (b) mixing with concrete.

is fitted under the loading frame followed by a load spreader. Seven numbers of steel 'I' section are placed below the load spreader for load distribution. Ten numbers of mild steel rods larger than slab dimensions are placed in longitudinal and transverse directions. Slabs are positioned in an upright position so that the movement in horizontal and vertical directions is restricted. A linear variable differential transducer (LVDT) is fixed at the midpoint of the slab to observe the deformation of the slab during the vertical monotonic loading. The load is applied at each $4 \mathrm{kN}$ increment. The displacement is noted in each load level. A load indicator is attached, and the corresponding deformation is measured
Table 1: Properties of glass fiber.

\begin{tabular}{lc}
\hline Description & Property \\
\hline Type of glass fiber & Chopped strand \\
Fiber length & $6 \mathrm{~mm}$ \\
Moisture (\%) & 0.2 \\
Sizing/Coupling system & Starch-based \\
Loss on ignition (\%) & 0.7 \\
\hline
\end{tabular}

through a data logger. Figure 4(a) presents the test setup of the slab under a loading frame. Figure 4(b) shows a view of LVDT placed at the middle of the slab. 
Table 2: Physical Properties of waste paper mass.

\begin{tabular}{lc}
\hline Physical properties & Value \\
\hline Density & 798 (g/cu.m) \\
Absorption (\%) & $89 \%$ \\
Specific gravity & 0.98 \\
\hline
\end{tabular}

TABLE 3: Chemical properties of waste paper mass (XRF analysis).

\begin{tabular}{lc}
\hline Composition & $\%$ \\
\hline Carbon-di-oxide & 86.2 \\
Silicon-di-oxide & 5.6 \\
Aluminium oxide & 6.95 \\
Magnesium oxide & 1.25 \\
\hline
\end{tabular}

\section{Results and Discussion}

\subsection{Physical Properties}

4.1.1. Percentage of Water Absorption. The test results of the water absorption test are shown in Figure 5. It is observed that if the percentage of paper mass gets increased, the water absorption also increased. This is due to the phenomenon of absorbing more water by the added paper mass. The results also implied that the addition of glass fiber reinforcement comparatively reduces the percentage of water absorption of the specimens. The maximum water absorption of $16.7 \%$ and $12.55 \%$ is observed in the cases with and without glass fiber addition, respectively. The reason for the higher absorption is due to the paper waste that contains the cellulose materials and thereby absorbs water and retains it for a longer time [34, 35].

4.1.2. Bulk Density. The results indicate that if the level of paper mass increases, the dry density gets reduced irrespective of with/without glass fiber addition. Figure 6 presents the test results of the concrete specimens at the age of 28 days. The density of the samples ranges between 2041 and $2548 \mathrm{~kg} / \mathrm{m}^{3}$ with glass fiber reinforcement. The density of concrete specimens without glass fiber incorporation displayed higher values than the latter. The lower density of paper mass causes a decrease in density and higher incorporation of paper mass into the concrete mixes [34].

\subsection{Mechanical Properties}

4.2.1. Compressive Strength. Figure 7 presents the compressive strength test results at the age of 28 days. The results infer that the $5 \%$ replacement of paper mass showed enhanced compressive strength, and further replacement beyond this point tends to reduce the strength of the concrete specimens. In the case of the glass fiber added concrete specimens, the increased addition of waste paper gradually decreases the compressive strength. 5\% replacement of paper mass provides $30.4 \%$ enhanced compressive strength at the age of 28 days than the conventional mix. However, $10 \%, 15 \%$, and $20 \%$ replacement levels show $40 \%, 66.4 \%$,
TABLE 4: Mix proportions for the waste paper concrete.

\begin{tabular}{lccccc}
\hline $\begin{array}{l}\text { Substitution } \\
(\%)\end{array}$ & $\begin{array}{c}\text { Paper } \\
(\mathrm{kg})\end{array}$ & $\begin{array}{c}\text { Cement } \\
(\mathrm{kg})\end{array}$ & $\begin{array}{c}\text { Sand } \\
(\mathrm{kg})\end{array}$ & $\begin{array}{c}\text { Coarse } \\
\text { aggregate } \\
(\mathrm{kg})\end{array}$ & $\begin{array}{c}\text { Water } \\
(\mathrm{kg})\end{array}$ \\
\hline 0 & 0 & 445 & & & 196 \\
5 & 22 & 423 & & & 186 \\
10 & 44 & 401 & 500 & 1223 & 176 \\
15 & 66 & 379 & & & 166 \\
20 & 89 & 356 & & & 156 \\
\hline
\end{tabular}

and $93.6 \%$ reduction in strength. Therefore, it can be concluded that the $5 \%$ replacement of paper mass with cement is the optimum replacement. This might be due to its dense microstructure which is evident from the micrograph (Figure 8) [3]. Paper is a natural polymer, and it contains abundant wood cellulose. Also, cellulose is in the form of sugar. In the polymeric chain links, it contains several hydroxyl groups. The reason for the compressive strength enhancement at $5 \%$ replacement level is the hydrogen bonding that coated with the cement matrix. For higher replacement levels, by applying the load, the hydrogen bond among the molecules of cellulose and water got broken and the reduction in strength occurred. Also, up to the optimum level, the water absorption by the paper mass promotes the water supply internally to the concrete mix, and more water is available for the hydration process and thereby improving mechanical characteristics. [34].

4.2.2. Split Tensile Strength. Figure 9 presents the test results of the split tensile strength of concrete specimens. The maximum split tensile strength is achieved at 5\% substitution of paper mass, and further increases in the paper mass decrease the strength. However, the addition of glass fiber reinforcement increases the split tensile strength in all the percentage replacement of paper mass. The replacement of 10,15 , and $20 \%$ of paper mass provides a reduction in split tensile strength of $23 \%, 40 \%$, and $83 \%$ at the age of 28 days compared to the conventional specimens. However, the addition of glass fibers increased the split tensile strength upto $15 \%$ replacement levels. An increase in the split tensile strength of $25 \%, 40 \%$, and $60 \%$ was observed at 5,10 , and $15 \%$ of glass fiber reinforcement addition. This increment in strength is due to the glass fibers that effectively filled the voids in the concrete and thereby interlocking of constituent materials of the concrete matrix. These results are in agreement with the previous work [34].

4.2.3. Flexural Strength. From Figure 10, it can be inferred that the addition of glass fiber reinforcement enhanced the 28-day flexural strength of concrete. The optimum percentage is observed at the $5 \%$ replacement. Further addition of glass fibers tends to reduce the flexural strength of specimens. It can be observed that the $5 \%$ replacement of paper mass showed an increased strength of $21.69 \%$ at the age of 28 days. The increased incorporation of paper mass tends to reduce the flexural strength after the optimum replacement level of 5\%. An increase in the flexural strength 


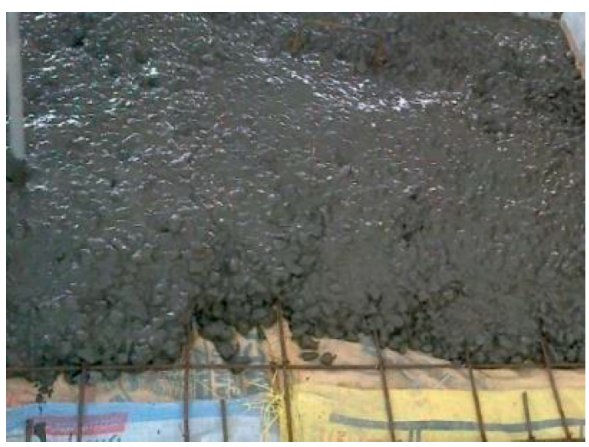

(a)

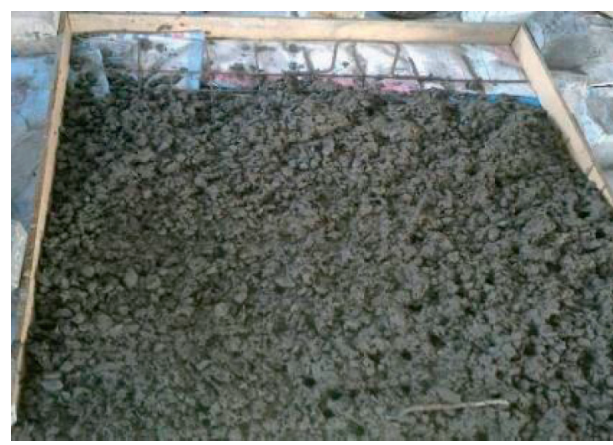

(b)

Figure 3: A view of making of waste paper concrete slab. (a) Conventional mix. (b) Glass-fiber reinforced mix.

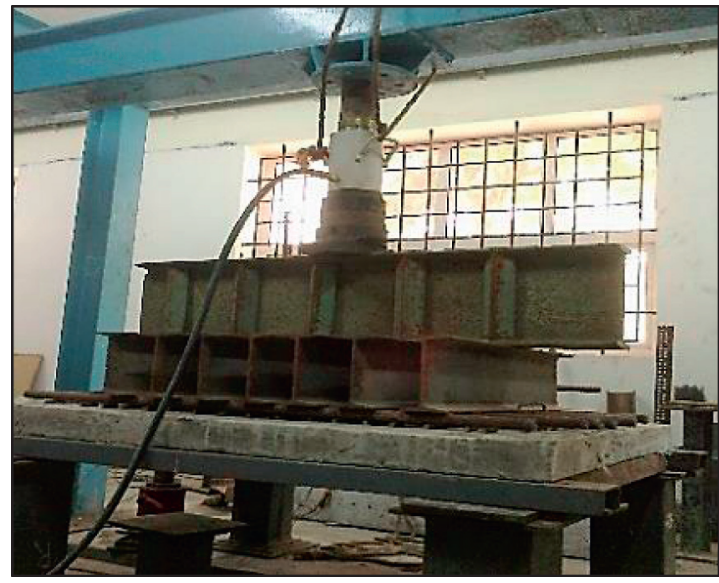

(a)

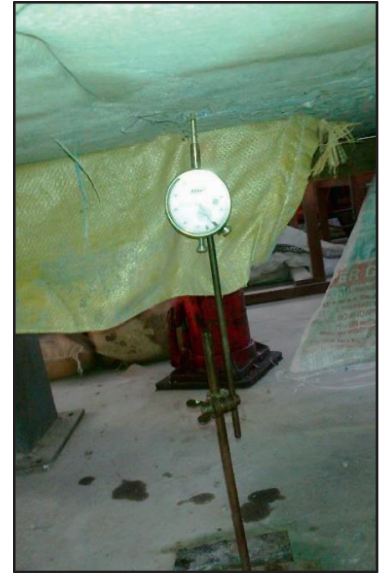

(b)

Figure 4: (a)Test setup of the slab under a loading frame. (b) LVDT at the middle of slab.

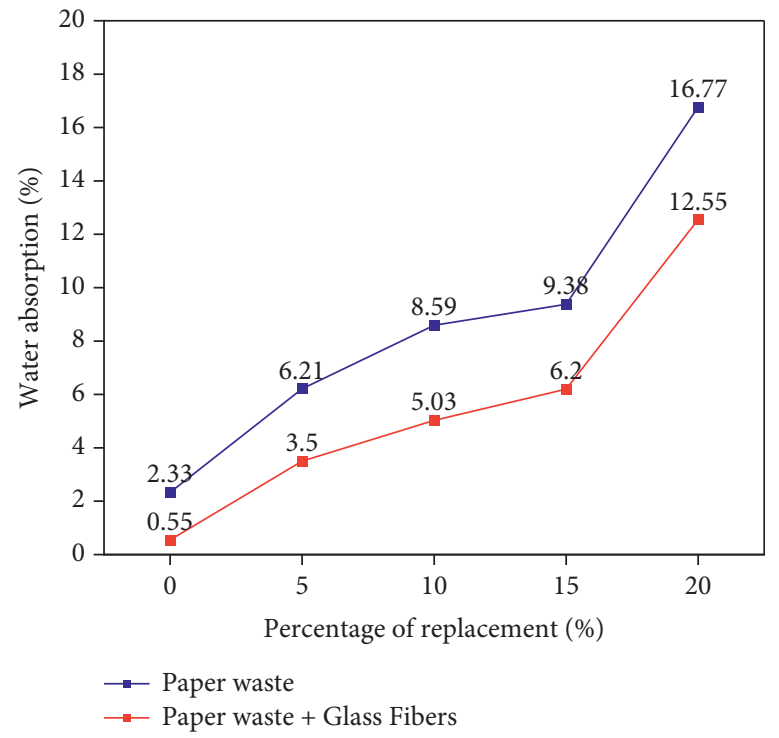

FIGURE 5: Water absorption test results.

of $13.36 \%$ is noted at the optimum replacement level. A reduction in the strength of $7.47 \%, 64.03 \%$, and $87 \%$ was noted for the $10 \%, 15 \%$, and $20 \%$ replacement levels. The reason for this reduction in the flexural strength may be due to the higher porosity of the waste papers which leads to more void space inside the matrix. [34]. 


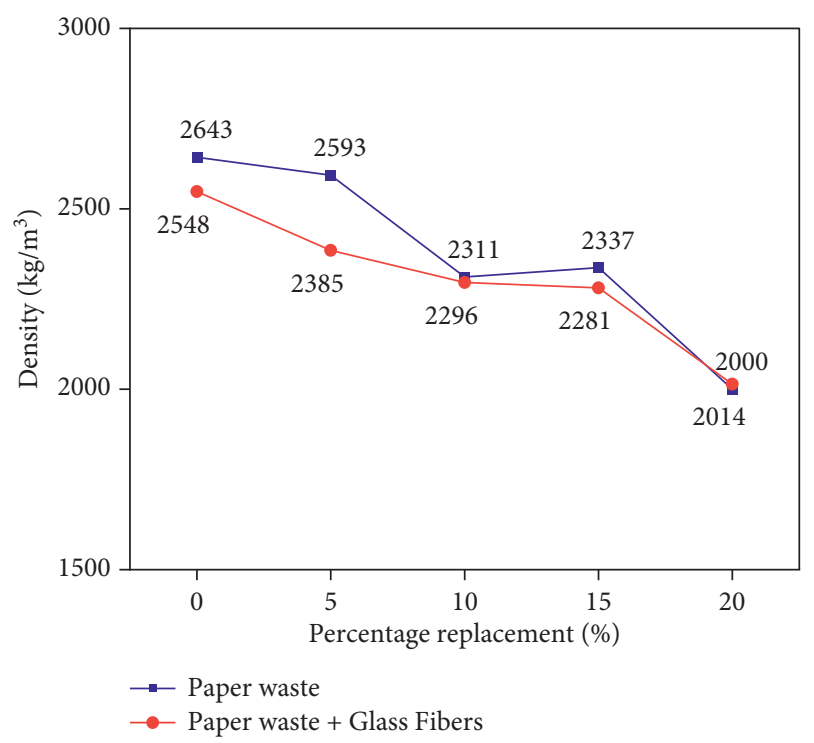

FIGURE 6: Bulk density results.

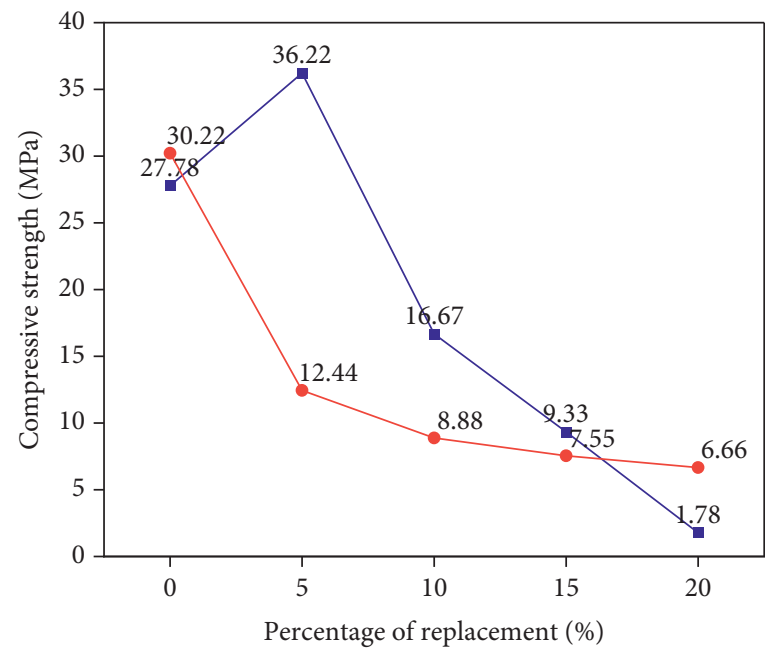

$\rightarrow$ Paper waste

- Paper waste + Glass Fibers

FIgURE 7: Test results of compressive strength.

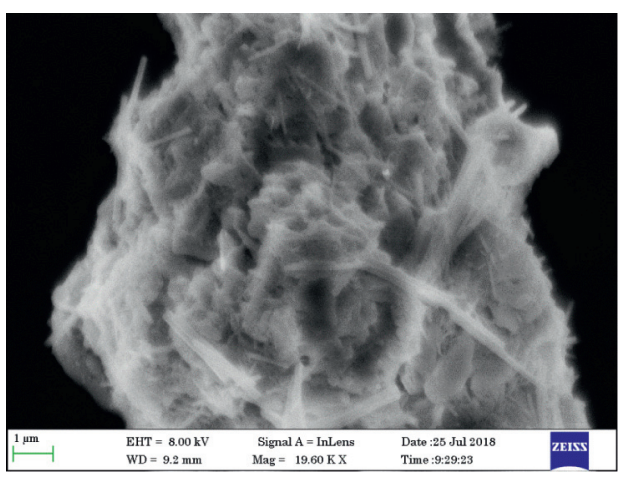

FIgURe 8: Micrograph of the optimum mix. 


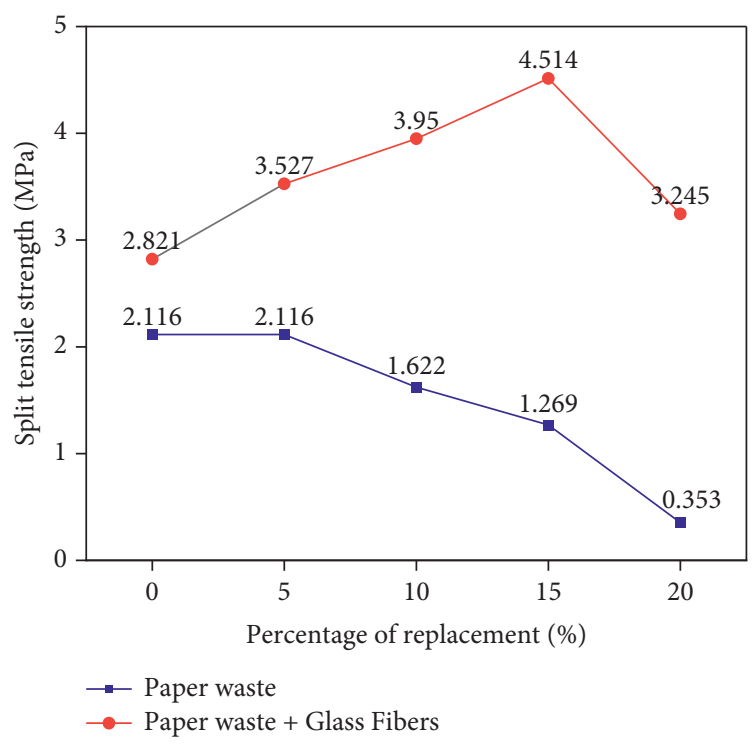

FIGURE 9: Split tensile strength results.

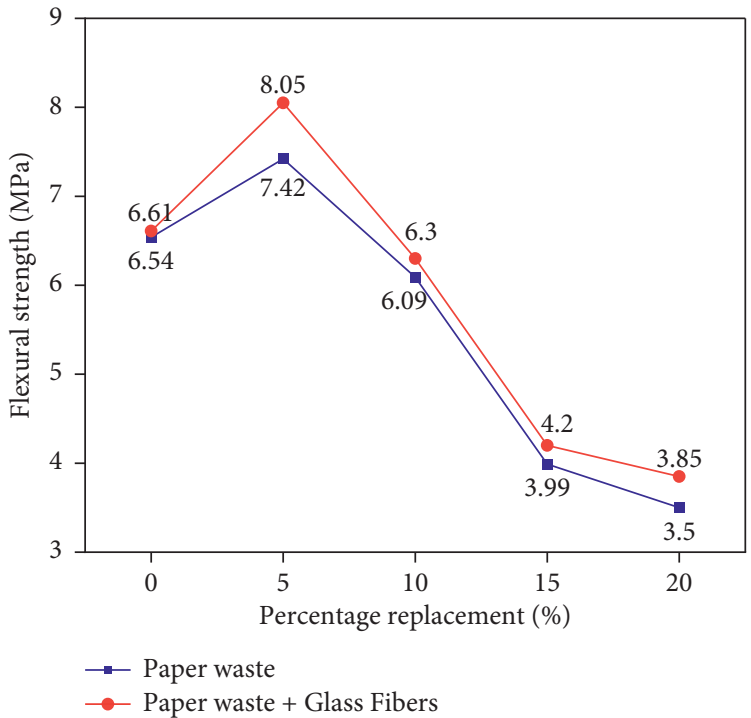

FIgURE 10: Flexural strength results.

4.2.4. Force-Deformation Characteristics of Slab Element. A vertical monotonic load is applied through a pumping unit. The deformation of the slab is measured in each $4 \mathrm{kN}$ load increment. The corresponding deformation properties are measured through the LVDT attached data acquisition system. Figure 11 presents the force-deformation characteristics of slab elements. The ultimate load-carrying capacity of the conventional slab without paper mass and glass fiber is $380 \mathrm{kN}$, whereas the slab which contains the paper mass sustains the ultimate load of $220 \mathrm{kN}$. Also, it is observed that the ultimate deflection corresponding to the ultimate load is $32.9 \mathrm{~mm}$ and $27.5 \mathrm{~mm}$, respectively, for conventional and glass fiber reinforced paper concrete slabs.

Figure 12(a) represents the deflected configuration of the conventional slab, and Figures 12(b) and 12(c) represent the typical crack pattern observed along the breadth and depth of the slab specimen, respectively. Figure 13 displays the brittle collapse of the glass fiber reinforced paper concrete slab. The stiffness of the glass fiber reinforced paper concrete slab is comparatively lesser than the conventional slab without paper mass addition. Also, in the higher magnitudes of load progresses, massive and wider cracks with large crack widths are observed in the glass-fiber reinforced paper concrete slab. However, in the conventional slab, the crack widths are less significant. The addition of waste paper mass disrupts the constituent materials in the concrete matrix. This makes the ingredients get weaker and loosen the compactness. Under the load increment, it magnifies the crack width and leads to enhanced and significant wide width of cracks. This phenomenon is comparatively lesser in the case of the conventional slab. 


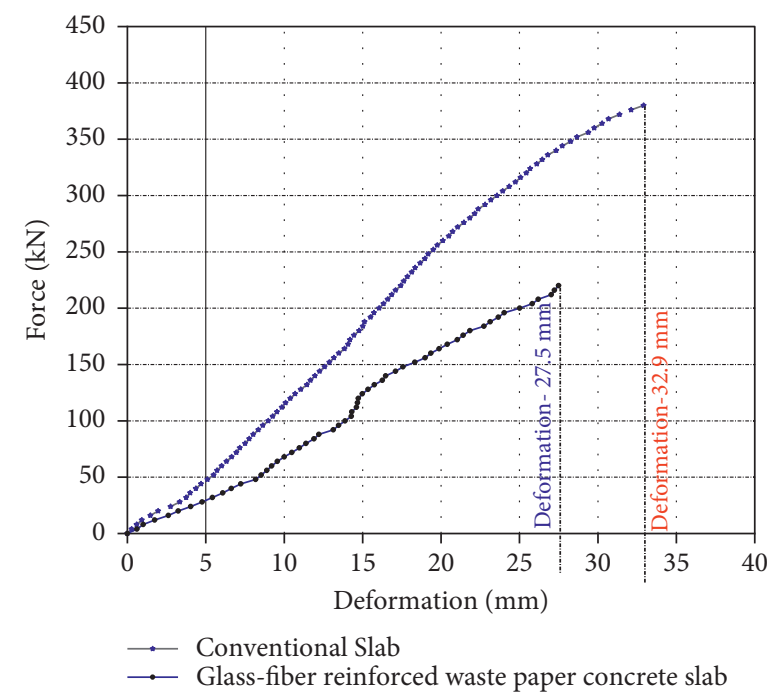

FIGURE 11: Force-deformation characteristics of the slab.

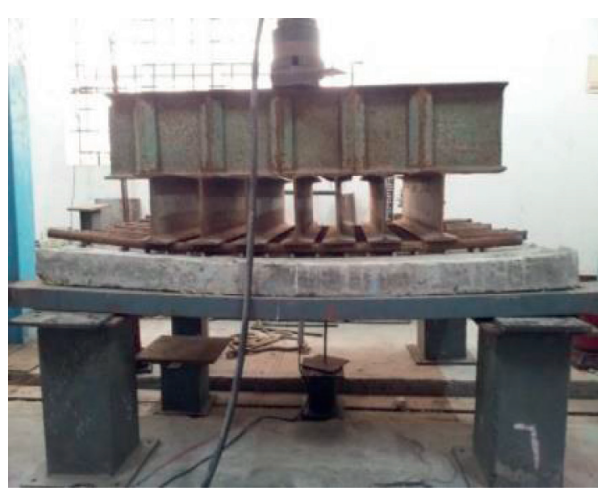

(a)

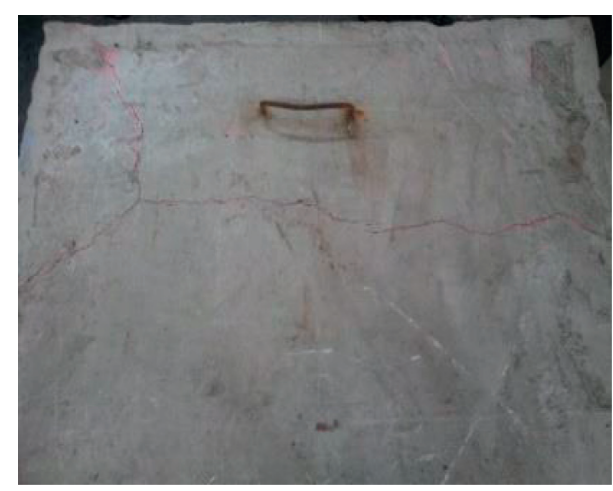

(b)

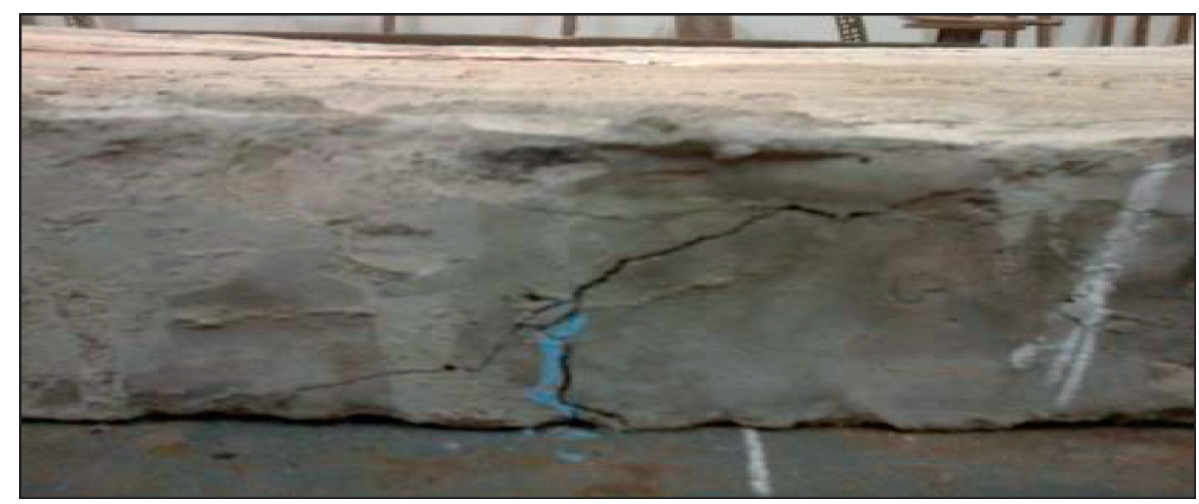

(c)

FIGURE 12: Failure pattern of the conventional slab. (a) Deflected configuration. (b) Crack propagation along the width. (c) Crack extension through the depth of the slab. 


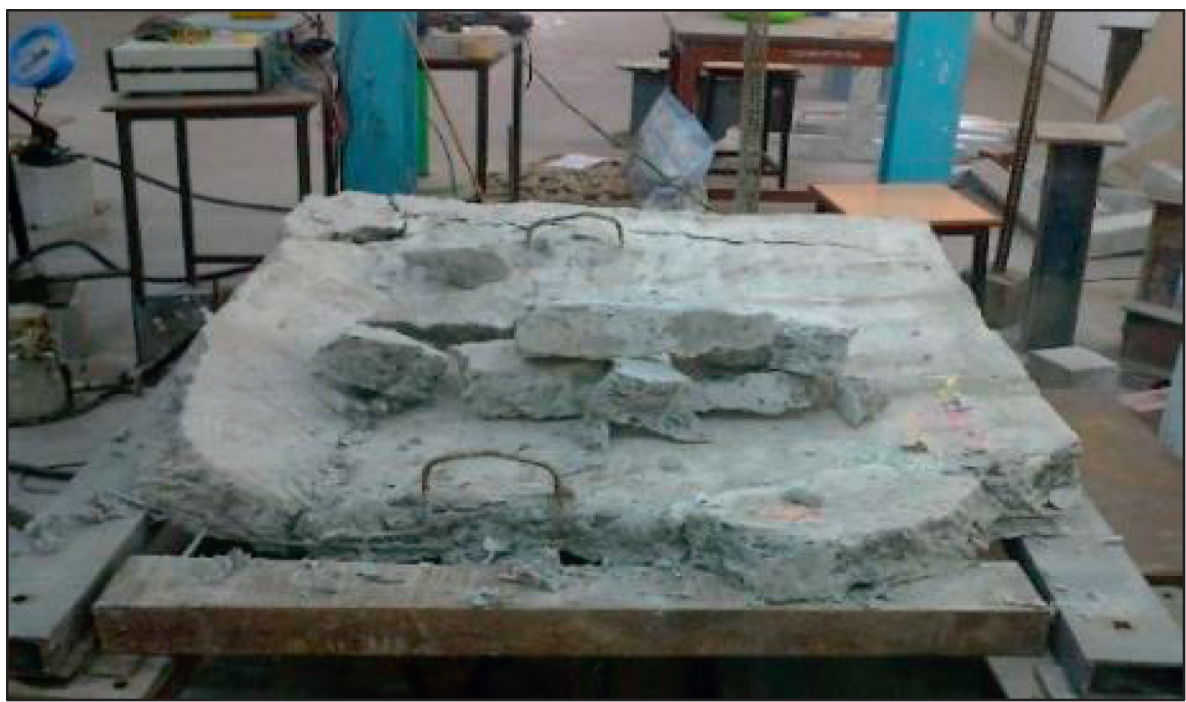

FIGURE 13: Final brittle collapse of glass fiber reinforced paper mass slab.

\section{Conclusions}

From the attained results, the following conclusions were drawn:

(i) The increase in the incorporation of paper mass tends to increase the percentage of water absorption gradually. However, the addition of glass-fiber reinforcement minimizes the water absorption characteristics for all the mixes. With the $0,5,10,15$, and $20 \%$ of paper mass replacement, there is an increase of $2.33 \%, 6.21 \%, 8.58 \%, 9.37 \%$, and $16.77 \%$ water absorption, respectively.

(ii) The incorporation of paper waste in the specimen made it denser by nearly $21 \%$.

(iii) The addition of paper waste in the mix leads to the increase in strength of the specimen by $30.4 \%$. The optimum value of the replacement is observed at $5 \%$. A similar trend is observed in the tensile and flexural strength results.

(iv) The addition of glass fibers upto $15 \%$ improves the split tensile strength of the mix.

(v) Wider cracks and brittle types of failure are observed in the paper waste-based concrete slab. However, in the conventional slab, cracks along the width and depth of the specimens are noted. Though the first crack load is observed in an earlier stage in the conventional slab than the paper concrete slab, the load-deformation analysis implies that the paper waste-based concrete slab sustains a lower ultimate load than the conventional slab.

(vi) Therefore, it is concluded that the addition of paper waste in the structural elements such as slab is not recommended for the usage of high load scenarios.

\section{Data Availability}

The data used to support the findings of this study are included within the article.

\section{Conflicts of Interest}

The authors declare that there are no conflicts of interest regarding the publication of this paper.

\section{Acknowledgments}

The authors thank REVA University, Bengaluru, for the technical assistance. The authors appreciate the support from Mettu University, Ethiopia. It was performed as a part of the Employment of Mettu University, Ethiopia.

\section{References}

[1] B. Ali, L. A. Qureshi, and S. U. Khan, "Flexural behavior of glass fiber-reinforced recycled aggregate concrete and its impact on the cost and carbon footprint of concrete pavement," Construction and Building Materials, vol. 262, Article ID 120820, 2020.

[2] G. K. Gupta and P. Shukla, "Insights into the resources generation from pulp and paper industry wastes: challenges, perspectives and innovations," Bioresource Technology, vol. 297, Article ID 122496, 2020.

[3] A. Ahmad, "Paper sludge, an environmentally sound alternative source of MK-based cementitious materials. A review," Construction and Building Materials, vol. 22, no. 7, pp. 37-48, 2008.

[4] R. Joshi and S. Ahmed, "Status and challenges of municipal solid waste management in India: a review," Cogent Environmental Science, vol. 2, no. 1, pp. 1139434-1139518, 2016.

[5] Akhilesh Kumar and Avlokita Agrawal, "Recent trends in solid waste management status, challenges, and potential for 
the future Indian cities-A review," Current Research in Environmental Sustainability, vol. 2, p. 100011, 2002.

[6] I. J. Ahluwalia and U. Patel, "Working paper No . 356 solid waste management in India an assessment of resource recovery and environmental impact isher judge ahluwalia," Indian Counc. Res. Int. Econ. Relations, vol. 356, pp. 1-48, 2018.

[7] A. Kumar and A. Agrawal, "Recent trends in solid waste management status, challenges, and potential for the future Indian cities - a review," Current Research in Environmental Sustainability, vol. 2, Article ID 100011, 2020.

[8] A. Gholampour, T. Ozbakkaloglu, O. Gencel, and T. D. Ngo, "Concretes containing waste-based materials under active confinement," Construction and Building Materials, vol. 270, no. xxxx, Article ID 121465, 2021.

[9] N. M. Ngwabie, Y. L. Wirlen, G. S. Yinda, and A. C. VanderZaag, "Quantifying greenhouse gas emissions from municipal solid waste dumpsites in Cameroon," Waste Management, vol. 87, pp. 947-953, 2019.

[10] F. N. Andrés, L. B. Beltramini, A. G. Guilarducci, M. S. Romano, and N. O. Ulibarrie, "Lightweight concrete: an alternative for recycling cellulose pulp," Procedia Materials Science, vol. 8, pp. 831-838, 2015.

[11] L. Agulló, A. Aguado, and T. Garcia, "Study of the use of paper manufacturing waste in plaster composite mixtures," Building and Environment, vol. 41, no. 6, pp. 821-827, 2006.

[12] B. Ahmadi and W. Al-Khaja, "Utilization of paper waste sludge in the building construction industry," Resources, Conservation and Recycling, vol. 32, no. 2, pp. 105-113, 2001.

[13] P. Faubert, S. Barnabé, S. Bouchard, R. Côté, and C. Villeneuve, "Pulp and paper mill sludge management practices: what are the challenges to assess the impacts on greenhouse gas emissions?" Resources, Conservation and Recycling, vol. 108, pp. 107-133, 2016.

[14] M. Likon, F. Cernec, J. Saarela, T. F. Zimmie, and J. Zule, "Use of paper mill sludgefor absorption of hydrophobic substances," in Proceedings of the 2nd International Conference on New Developments in Soil Mechanics and Geotechnical Engineering, pp. 526-533, Lefkosa, North Cyprus, 2009.

[15] J. Soucy, A. Koubaa, S. Migneault, and B. Riedl, "The potential of paper mill sludge for wood-plastic composites," Industrial Crops and Products, vol. 54, pp. 248-256, 2014.

[16] M. Pervaiz and M. Sain, "Recycling of paper mill biosolids: a review on current practices and emerging biorefinery initiatives," Clean - Soil, Air, Water, vol. 43, no. 6, pp. 919-926, 2015.

[17] S. Yan, K. Sagoe-Crentsil, and G. Shapiro, "Reuse of de-inking sludge fromwastepaper recycling in cement mortar products," Journal of Environmental Management, vol. 92, no. 8, pp. 2085-2090, 2011.

[18] W. Li, Q. Yue, P. Tu et al., "Adsorption characteristics of dyes in columns of activated carbon prepared from paper mill sewage sludge," Chemical Engineering Journal, vol. 178, pp. 197-203, 2011.

[19] H. Karimi, F. Gauvin, H. J. H. Brouwers, R. Cardinaels, and Q. Yu, "On the versatility of paper pulp as a viscosity modifying admixture for cement composites," Construction and Building Materials, vol. 265, Article ID 120660, 2020.

[20] S. Haider, M. S. Danish, and R. Sharma, "Assessing energy efficiency of Indian paper industry and influencing factors: a slack-based firm-level analysis," Energy Economics, vol. 81, pp. 454-464, 2019.

[21] F. Corcelli, J. Vehmas, and S. Ulgiati, "Energy efficiency and environmental assessment of papermaking from chemical pulp - a Finland case study," Journal of Cleaner Production, vol. 198, pp. 96-111, 2018.

[22] V. S. Nadh, C. Krishna, L. Natrayan et al., "Structural behavior of nanocoated oil palm shell as coarse aggregate in lightweight concrete," Journal of Nanomaterials, vol. 2021, Article ID 4741296, 7 pages, 2021.

[23] N. D. K. R. Chukka, L. Natrayan, and W. D. Mammo, "Seismic fragility and life cycle cost analysis of reinforced concrete structures with a hybrid damper," Advances in Civil Engineering, vol. 2021, Article ID 4195161, 17 pages, 2021.

[24] B. Fuller, A. Fafitis, and J. Santamaria, "Structural properties of a new material made of waste paper," Build. Integr. Solut., vol. 3, 2006.

[25] S. A. S. I. N. Gorgis, "Properties of papercrete," ARPN J. Eng. Appl. Sci.vol. 12, no. 24, pp. 7401-7411, 2017.

[26] A. Lawrence, T. Nehler, E. Andersson, M. Karlsson, and P. Thollander, "Drivers, barriers and success factors for energy management in the Swedish pulp and paper industry," Journal of Cleaner Production, vol. 223, pp. 67-82, 2019.

[27] P. Bajpai, "Uses of recovered paper other than papermaking," Recycling and Deinking of Recovered Paper, vol. 16, pp. 283295, 2014.

[28] D. Gavrilescu, "Energy from biomass in pulp and paper mills," Environmental Engineering and Management Journal, vol. 7, no. 5, pp. 537-546, 2008.

[29] Z. Yuan and Y. Jia, "Mechanical properties and microstructure of glass fiber and polypropylene fiber reinforced concrete: an experimental study," Construction and Building Materials, vol. 266, Article ID 121048, 2021.

[30] T. Simões, H. Costa, D. Dias-da-Costa, and E. Júlio, "Influence of fibres on the mechanical behaviour of fibre reinforced concrete matrixes," Construction and Building Materials, vol. 137, pp. 548-556, 2017.

[31] N. M. Ayash, A. M. Abd-Elrahman, and A.-E. Soliman, "Repairing and strengthening of reinforced concrete cantilever slabs using Glass Fiber-Reinforced Polymer (GFRP) wraps," Structures, vol. 28, pp. 2488-2506, 2020.

[32] M. Madhkhan and R. Katirai, "Effect of pozzolanic materials on mechanical properties and aging of glass fiber reinforced concrete," Construction and Building Materials, vol. 225, pp. 146-158, 2019.

[33] BIS:1489 (Part 1), Portland-pozzolana Cement-Specification, Bur. Indian Stand., New Delhi, India, 1991.

[34] S. R. Ahmedizat, A. B. Al-Zubaidi, and A. A. Al-Tabbakh, "Fabrication green concrete by Recycled wastepaper," IOP Conference Series: Materials Science and Engineering, vol. 870, no. 1, Article ID 012146, 2020.

[35] T. Cardinale, M. D'Amato, R. Sulla, and N. Cardinale, "Mechanical and physical characterization of papercrete as new eco-friendly construction material," Applied Sciences, vol. 11, no. 3, pp. 1011-11, 2021. 